\title{
KẾT QUẢ TRUNG HẠN PHẪU THUẠTT FONTAN VỚI ỐNG NỐI NGOÀI TIM TẠI TRUNG TÂM TIM MẠCH - BỆNH VIỆN E
}

\author{
Đố Anh Tiến", Đoàn Quốc Hung ${ }^{* *}$, Lê Ngoc Thành*
}

\section{TÓM TĂT:}

Phẫu thuật Fontan là tạo đường đưa máu trực tiếp từ tĩnh mạch hệ thống lên phổi mà không qua tâm thất phải. Được coi là phẫu thuật thì cuối cho bệnh nhân tim bẩm sinh dạng một tâm thất. Đã có rất nhiều thay đổi về kỹ thuật thực hiện phẫu thuật fontan. Ngày nay chủ yếu các trung tâm phẫu thuật tim trên thế giới thực hiện phẫu thuật fontan với ống nối ngoài tim bằng mạch nhân tạo. Phương pháp nghiên cứu: mô tả.Tại Trung tâm tim mạch bệnh viện $E$, từ tháng 8/2012 đến tháng 12/2015 đã phẫu thuật Fontan với ống nối ngoài tim cho 61 bệnh nhi $(\mathrm{BN})$ bị tim bẩm sinh dạng một tâm thất. Kết quả nghiên cứu: $59 \mathrm{BN}$ $(96,72 \%)$ sống sau mổ, được theo dõi với thời gian trung bình $18 \pm 10,28$ tháng, ngắn nhất là 6 tháng và dài nhất là 45 tháng. Không có $\mathrm{BN}$ tử vong; $88,14 \%$ BN không bị tím môi và đầu chi; 94,92\% BN suy tim độ I và II. Biến chứng gặp phải trong quá trình theo dõi: loạn nhịp sau mổ $(3,39 \%)$, tai biến mạch não $(3,39 \%)$, hội chứng mất protein ruột $(3,39 \%)$, thất bại Fontan $5,08 \%$.Kết luận: kết quả trung hạn tốt của phẫu thuật Fontan với ống nối ngoài tim bằng mạch nhân tạo Gore-Tex.

\section{THE MIDTERM RESULTS OF} EXTRACARDIAC FONTAN IN

\section{CARDIOVASCULAR CENTER - E HOSPITAL}

Background: The Fontan procedure is total cavopulmonary connection, this technique is the end stage that application for all forms of single ventricle hearts. There are a lot of modified Fontan procedure, but now the extracadiac fontan technique is used popular in the world. Method: descriptive research was performed in
Cardiovascular center- Ehospital: from August 2012 to December 2015, 61 consecutive pediatric patients with single ventricle who underwent extracardiac Fontan operation. Result: Survival rate was $96,72 \%$. The mean time follow up was 18 months( range from 6 months to 45 months). No late death; 84,14\% without bluish coloration of the skin; 94,92 \% at the stage I, II of heart failure. Late complications: Arrhythia - 3,39\%; Thrombolism - 3,39\%; Protein enteropathy losing $-3,39 \%$; Fontan failure $-5,08 \%$.

Conclusions: The midterm of extracadiac fontan was satisfactory without death and low late complications.

Key word: Extracardiac Fontan.

\section{I. ĐẠT VẤN ĐỀ:}

Tim bẩm sinh phức tạp dạng một tâm thất được mô tả là nhóm bệnh tim bẩm sinh có thể có một hoặc hai tâm thất song chỉ có một tâm thất đủ kích thước và chức năng bơm máu đến các cơ quan của cơ thể như các bệnh: Thiểu sản van ba lá, hội chứng thiểu sản tim trái, teo động mạch phổi không có thông liên thất. Phẫu thuật Fontan được thực hiện đầu tiên năm 1968 cho bệnh nhân (BN) bị thiểu sản van ba lá và được công bố năm 1971, là kỹ thuật đưa trực tiếp máu từ tĩnh mạch hệ thống vào động mạch phổi (ĐMP) mà không qua tâm thất phải và được coi là phẫu thuật thì cuối cho BN tim bẩm sinh dạng một tâm thất [1]. Đã có rất nhiều thay đổi và cải tiến kỹ thuật làm

\footnotetext{
* Trung tâm tim mạch bệnh viện E

** Bộ môn Ngoại, ĐHY Hà Nội

Ngưòi chịu trách nhiệm khoa học: PGS.TS. Đoàn Quốc Hung

Ngày nhận bài:10/02/2017 - Ngày Cho Phép Đăng: 10/03/2017

Phản Biện Khoa hoc: PGS.TS. Đặng Ngọc Hùng

GS.TS. Bùi Đúc Phú
} 
đường đưa máu từ tĩnh mạch chủ dưới lên ĐMP như nối tiểu nhĩ phải với ĐMP, kỹ thuật Fontan với đường hầm trong tim....

Năm 1990, Marceletti thực hiện nối tĩnh mạch chủ dưới với động mạch phổi bằng ống nối ngoài tim (Extra cardiac conduit technique) với các ưu điểm như giảm tỷ lệ tử vong, biến chứng rối loạn nhịp tim, tắc mạch [2]. Tại trung tâm tim mạch - Bệnh viện $\mathrm{E}$, chúng tôi đã tiến hành phẫu thuật Fontan với ống nối ngoài tim bằng mạch nhân tạo Gore-Tex từ tháng $8 / 2012$, chúng tôi thông báo kết quả trung hạn của phẫu thuật này.

\section{II. ĐỐI TƯợNG VÀ PHƯƠNG PHÁP NGHIÊN CÚU \\ Đối tượng:}

Từ tháng $8 / 2012$ đến tháng $12 / 2015$, có 61 BN nhi được chẩn đoán bệnh tim bẩm sinh dạng một tâm thất đã phẫu thuật Glenn hai hướng được phẫu thuật Fontan với ống nối ngoài tim bằng mạch nhân tạo Gore-Tex.
Phương pháp nghiên cứu:

Phương pháp mô tả:

+ Các chỉ tiêu nghiên cứu: chẩn đoán, tỷ lệ tử vong ngay sau mổ, các chỉ số khi khám lại ở lần khám gần nhất tính đến ngày 30/6/2016: tỷ lệ sống, bão hòa ôxy ( $\mathrm{SpO} 2)$, mức độ suy tim, các biến chứng gặp phải: loạn nhịp tim, huyết khối, hội chứng mất protein ruột, thất bại Fontan.

+ Phương pháp phẫu thuật Fontan với ống nối ngoài tim bằng mạch nhân tạo.

- BN được mở xương ức và đặt hệ thống tuần hoàn ngoài cơ thể như phẫu thuật tim kinh điển.

Tiến hành cắt TMC dưới khỏi nhĩ phải, khi cắt để lại phần TMC dưới càng dài càng tốt, khâu đóng mỏm nhĩ phải. TMC dưới được nối với mạch nhân tạo, miệng nối tận - tận. Cắt đôi ĐMP sát chạc ba ĐMP, mở rộng sang hai bên ĐMP phải và trái ra gần rốn phổi. Nối đầu mạch nhân tạo với ĐMP bằng miệng nối tận- bên [3],[4].

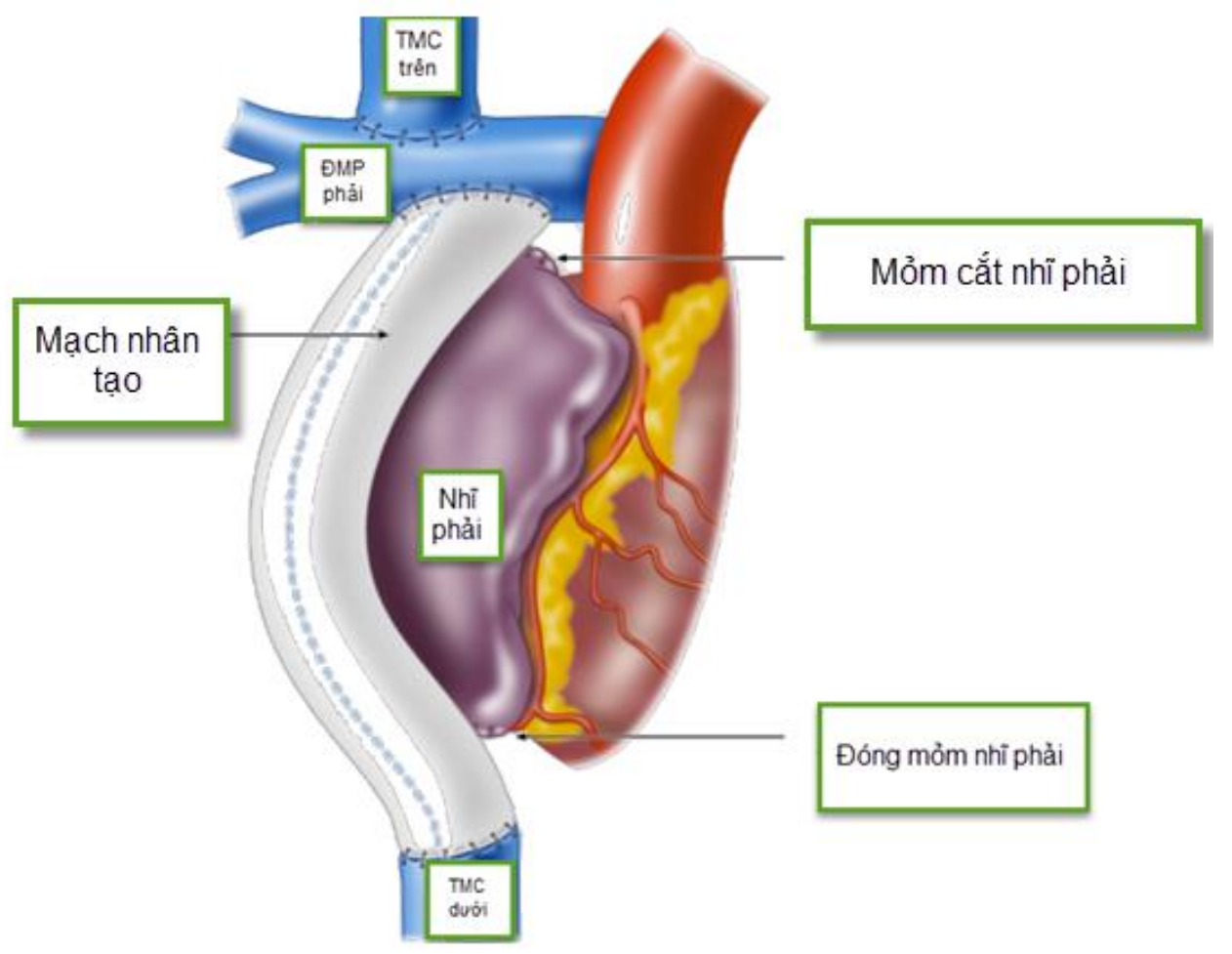

Hình 1: Các thao tác phẫu thuật Fontan với ống nối ngoài tim [2]

\section{III.KẾT QUẢ NGHIÊN CÚ'U}


+ Nghiên cứu $61 \mathrm{BN}$ có tuổi trung bình 5,59 tuổi (2 tuổi - 14 tuổi), BN nam chiếm 57,38\%; BN nữ chiếm $42,62 \%$.

+ Chẩn đoán

Bảng 3.1. Chẩn đoán bệnh

\begin{tabular}{|l|l|l|l|}
\hline Chẩn đoán & $\mathbf{n}$ & Tỷ lệ \% & $\begin{array}{l}\text { Tần số } \\
\text { cộng dồn }\end{array}$ \\
\hline Thất phải hai đường ra, đảo gốc, hẹp phổi & 16 & 26,23 & 26,23 \\
\hline Thiểu sản van ba lá & 14 & 22,95 & 49,18 \\
\hline Bất tương hợp nhĩ thất, đảo gốc, hẹp phối & 14 & 22,95 & 72,13 \\
\hline Thiểu sản van hai lá & 7 & 11,48 & 83,61 \\
\hline Kênh nhĩ thất chung, hẹp phổi & 3 & 4,92 & 88,53 \\
\hline Heterotaxy & 2 & 3,28 & 91,81 \\
\hline Thất trái hai đường vào & 2 & 3,28 & 95,09 \\
\hline Teo ĐMP vách liên thất nguyên vẹn & 2 & 3,28 & 98,37 \\
\hline Thất phải hai đường vào & 1 & 1,63 & 100 \\
\hline Tổng số & 61 & 100 & \\
\hline
\end{tabular}

+ Mức độ suy tim và $\mathrm{SpO} 2$ trước mổ: $61(100 \%) \mathrm{BN}$ đều bị tím môi và đầu chi với $\mathrm{SpO}_{2}$ trung bình: $83 \pm 3,32 \%(75 \%-90 \%)$.

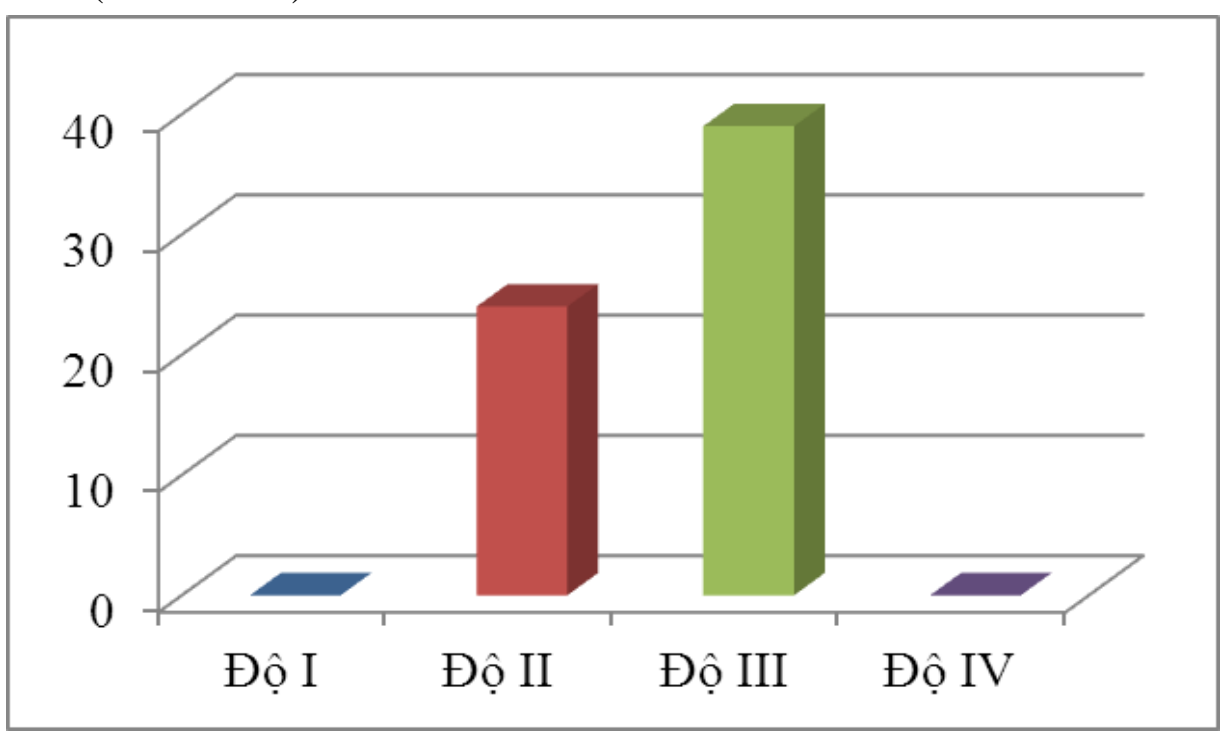

Biểu đồ 3.1: Múcc độ suy tim trước mổ

+ Tỷ lệ sống ngay sau mổ: $96,72 \%$, có 2 BN tử vong tại phong hồi sức sau mổ.

+ Thời gian theo dõi trung bình 18 tháng (6 tháng - 45 tháng). Không có $\mathrm{BN}$ tử vong.

+ Mức độ tím môi và đầu chi:

Bảng 3.2: Mức độ tim môi và đầu chi khi khám lại 


\begin{tabular}{|l|l|l|}
\hline Tím môi và đầu chi & $\mathbf{n}$ & Tỷ lệ\% \\
\hline Có & 7 & 11,86 \\
\hline Không & 52 & 88,14 \\
\hline Tổng số & 59 & 100 \\
\hline
\end{tabular}

+ Mức độ suy tim khi khám lại

Bảng 3.3: Mức độ suy tim khi khám lại

\begin{tabular}{|l|l|l|l|}
\hline Độ suy tim & $\mathbf{n}$ & Tỷ lệ\% & Tần số cộng dồn \\
\hline Độ I & 43 & 72,88 & 72,88 \\
\hline Độ II & 13 & 22,04 & 94,92 \\
\hline Độ III & 2 & 3,39 & 98.31 \\
\hline Độ IV & 1 & 1,69 & 100 \\
\hline Tổng số & $\mathbf{5 9}$ & $\mathbf{1 0 0}$ & \\
\hline
\end{tabular}

+ Biến chứng

Bảng 3.4: Các biến chứng muộn

\begin{tabular}{|l|l|l|}
\hline Biến chứng & n & Tỷ lệ \% \\
\hline Tử vong & 0 & 0 \\
\hline Loạn nhịp & 2 & 3,39 \\
\hline Hội chứng mất protein ruột & 2 & 3,39 \\
\hline Tai biến mạch não & 2 & 3,39 \\
\hline Thất bại Fontan & 3 & 5,08 \\
\hline
\end{tabular}

\section{IV.BÀN LUẬN}

+ Tỷ lệ sống trong quá trình theo dõi: Không có trường hợp nào bị tử vong trong thời gian theo dõi, tỷ lệ sống là $100 \%$. Nghiên cứu của $\mathrm{S}$. Ocello theo dõi $100 \mathrm{BN}$ sau phẫu thuật Fontan với ống nối ngoài tim trong thời gian 39 tháng sau mổ có tỷ lệ sống $100 \%$ [5], nghiên cứu của Yves d' Udekem với thời gian theo dõi trung bình 12 năm thấy tỷ lệ sống của nhóm phẫu thuật Fontan với ống nối ngoài tim là $100 \%$, trong đó với phẫu thuật Fontan kinh điển là $81 \%$ và phẫu thuật Fontan với đường hầm trong tim là 94\% [2]. Theo nghiên cứu của Madhusuda Ganigara với thời gian theo dõi trung bình 14 tháng tỷ lệ sống sót là $100 \%$ [6], kết quả này cũng giống như nghiên cứu của G.S. Hass với thời gian theo dõi trung bình là 64 tháng và không có trường hợp nào tử vong[7]. Như vậy kết quả sống trong thời gian theo dõi của chúng tôi cũng tương tự như của các tác giả trên.

+ Mức độ suy tim khi khám lại có 94,92\% BN suy tim độ I và II, có 2 BN chiếm 3,39\% suy tim độ III và $1 \mathrm{BN}$ chiếm $1,69 \%$ suy tim độ IV. Khi so sánh mức độ suy tim trên lâm sàng khi khám lại so với trước mổ chúng tôi không thấy sự khác biệt có ý nghĩa thống kê, song tỷ lệ BN bị suy tim nặng (Độ III, IV) trong thời gian theo dõi sau mổ đã giảm đáng kể. Theo kết quả theo dõi của P.G. Sfyridis sau mổ 62,7 tháng có $98,21 \%$ BN suy tim độ I và III, chỉ có $1,79 \%$ BN bị suy tim độ 
III, không có BN suy tim độ IV [8], nghiên cứu của G.S. Haas có $87 \%$ suy tim độ I, suy tim độ II có $9 \%$ và $4 \%$ suy tim độ III [7]; của Ujjwal $\mathrm{K}$. Chowdhury có $88 \% \mathrm{BN}$ suy tim mức độ I và II [9], còn nghiên cứu của Soo-Jin Kim có 95,2\% BN suy tim độ I và 4,8\% $\mathrm{BN}$ suy tim độ II [10]. Như vậy qua các nghiên cứu thấy rằng mức độ suy tim sau mổ trong thời gian theo dõi đều cải thiện và duy trì ở mức độ nhẹ.

+ Bão hòa ôxy: Trong nghiên cứu có $88,14 \%$ $\mathrm{BN}$ không bị tím môi và đầu chi, $11,86 \% \mathrm{BN}$ vẫn còn tím môi và đầu chi khi khám lại. Chỉ số $\mathrm{SpO} 2$ khi thở khí trời trung bình là $95,63 \%$, thấp nhất là $89 \%$. Theo nghiên cứu của Iki Adachi, SpO2 trung bình là 94\% [11], của G.S. Haas là 97\% [7], của $\mathrm{S}$. Ovroutski là 95\% [12]. Như vậy kết quả nghiên cứu của chúng tôi cũng tương tự các tác giả trên. Hầu hết BN sau phẫu thuật Fontan đều cải thiện tình trạng thiếu ôxy mạn tính với mức độ $\mathrm{SpO} 2$ cao. Những trường hợp $\mathrm{SpO} 2$ thấp do cửa sổ giữa ống mạch nhân tạo và tâm nhĩ còn thông do vậy còn luồng máu từ tĩnh mạch hệ thống sang bên tâm nhĩ, gây ra hiện tượng máu trộn ở tầng nhĩ, theo thời gian hầu như cửa sổ giữa tâm nhĩ và ống mạch nhân tạo sẽ tự đóng nếu như không còn hiện tượng tăng áp lực ĐMP sau mổ. Một nguyên nhân nữa gây ra hiện tượng tím môi và đầu chi do hiện tượng thông của động mạch và tĩnh mạch trong nhu mô phổi [13].

+ Huyết khối và tai biến mạch não: nghiên cứu của chúng tôi có $2(3,39 \%) \mathrm{BN}$ bị tai biến mạch não trong quá trình theo dõi (1 BN sau mổ 6 tháng và $1 \mathrm{BN}$ sau mổ 11 tháng), trong đó $1 \mathrm{BN}$ siêu âm cửa sổ giữa ống mạch nhân tạo và tâm nhĩ còn thông, một $\mathrm{BN}$ cửa sổ đã đóng. Hình ảnh chụp cắt lớp vi tính sọ não đều có hình ảnh nhồi máu não. Biểu hiện lâm sàng có liệt không hoàn toàn nửa người. Được điều trị phục hồi chức năng, hiện tại $1 \mathrm{BN}$ đã hồi phục hoàn toàn, $1 \mathrm{BN}$ chưa hồi phục hoàn toàn. Theo nghiên cứu của Soo-Jin Kim có $6,5 \%$ BN bị tai biến mạch não trong đó chủ yếu xảy ra ở năm đầu tiên sau mổ [10], nghiên cứu của Ujjwal K. Chowdhury tỷ lệ bị huyết khối là 4,6\% [9], của Marrone C trên $1075 \mathrm{BN}$ được phẫu thuật Fontan với miệng nối ngoài tim thấy tỷ lệ bị huyết khối là $5,2 \%$ trong thời gian theo dõi từ 2 tháng - 144 tháng [14]. Huyết khối sau phẫu thuật Fontan là một biến chứng nặng dẫn đến nguy cơ tử vong cao cũng như tai biến mạch não[15],[16]. Biến chứng này được mô tả lần đầu tiên từ năm 1978, song đến ngày nay các dấu hiệu để phát hiện sớm hình ảnh huyết khối rất khó khăn [17],[18]. Theo M.L. Jacobs huyết khối sau phẫu thuật Fontan có hai dạng: một là huyết khối hình thành trong ống mạch nhân tạo, TMC và ĐMP, dạng huyết khối này có thể nằm tại chỗ gây ra cản trở dòng chảy từ $\mathrm{TM}$ hệ thống lên ĐMP, cũng có thể nó di chuyển qua cửa sổ sang bên tuần hoàn hệ thống gây tắc mạch tạng; dạng thứ hai là huyết khối hình thành trong buồng tim, đặc biệt là túi cùng của thân ĐMP khi phẫu thuật Fontan thường cắt hoặc thắt thân ĐMP sát chạc ba ĐMP do đó hình thành túi cùng ở thân ĐMP dễ gây hình thành huyết khối [19]. Để phòng ngừa biến chứng huyết khối sau mổ, nên sử dụng thuốc chống đông. Tất cả $\mathrm{BN}$ của chúng tôi đều được sử dụng thuốc chống ngưng tập tiểu cầu (Aspergic) và duy trì liên tục. Một số nghiên cứu thấy rằng tỷ lệ $\mathrm{BN}$ bị huyết khối sau phẫu thuật Fontan với ống nối ngoài tim từ $20 \%$ đến $23 \%$ nếu không duy trì thuốc chống đông [17],[18], chính vì vậy một số nghiên cứu khuyến cáo nên duy trì thuốc chống đông sau mổ [10],[8],[18].

+ Loạn nhịp tim: các rối loạn nhịp tim sau phẫu thuật Fontan bao gồm cơn nhịp nhanh trên thất, rung nhĩ nhanh, suy nút xoang, nhịp bộ nối... Đây là một trong những nguyên nhân chủ 
yếu gây tử vong khi theo dõi lâu dài. Nghiên cứu của chúng tôi có $2 \mathrm{BN}$ chiếm 3,39\% bị rối loạn nhịp tim trong quá trình theo dõi, $1 \mathrm{BN}$ bị suy nút xoang, $1 \mathrm{BN}$ bị nhịp bộ nối, cả $2 \mathrm{BN}$ này đều được chẩn đoán trên điện tâm đồ, và trên Holter điện tim 24 giờ. Nghiên cứu của Jeong Ryul Lee tỷ lệ này là $11,2 \%$ ở nhóm $\mathrm{BN}$ phẫu thuật Fontan với ống nối ngoài tim [20], của Soo-Jin Kim tỷ lệ này là $16 \%$ [10], trong nghiên cứu của Azakie và cộng sự tỷ lệ này là $13 \%$ [21]. Như vậy tỷ lệ $\mathrm{BN}$ bị loạn nhịp tim của chúng tôi thấp hơn của các tác giả trên bởi vì thời gian theo dõi sau phẫu thuật của chúng tôi còn ngắn

+ Hội chứng mất protien ruột: Nghiên cứu của chúng tôi có $2(3,39 \%)$ BN có hội chứng mất protein ruột xuất hiện sau mổ 12 tháng và 16 tháng. Các triệu chứng bao gồm: phù 2 chi dưới, tràn dịch màng bụng, xét nghiệm albumin máu của $\mathrm{BN}$ là $22 \mathrm{~g} / \mathrm{L}$ và $20 \mathrm{~g} / \mathrm{L}$. mất protein ruột (Protein-Losing Enteropathy) là một biến chứng nặng và điều trị khó khăn sau phẫu thuật Fontan, tần suất có thể gặp từ $5 \%$ đến $15 \%$ và nguy cơ tử vong cao tới $50 \%$ ở $\mathrm{BN}$ được chẩn đoán hội chứng này sau 5 năm [22],[23],[24]. Do áp lực của TM hệ thống tăng cao dẫn đến tăng áp lực trong hệ thống bạch mạch làm mất protein như là albumin, immunoglobin, các yếu tố đông máu ở hệ thống đường tiêu hóa. Do mất protein gây ra hiện tượng phù ngoại vi, tràn dịch đa màng (màng bụng, màng phổi, màng tim...), sụt cân, tiêu chảy kéo dài và hội chứng kém hấp thu [25]. Điều trị bao gồm nội khoa ( bù albumin, corticotd), can thiệp mở cửa sổ, phẫu thuật mở cửa sổ.

+ Thất bại Fontan được định nghĩa gồm các trường hợp tử vong, các trường hợp phải mổ lại có liên quan đến ống mạch nhân tạo hoặc phải làm thêm cầu nối chủ - phổi (Taken down Fontan procedure), các trường hợp phải ghép tim, $\mathrm{BN}$ có suy tim độ III, IV. Theo nghiên cứu của chúng tôi có 3(5,08\%) BN bị thất bại Fontan trong quá trình theo dõi, 2 BN có suy tim độ III (1 BN bị tai biến mạch não, $1 \mathrm{BN}$ bị hội chứng mất protein ruột), 1 BN bị suy tim độ IV (BN bị hội chứng mất protein ruột, đã được điều trị song không hiệu quả, có chỉ định ghép tim). Theo nghiên cứu của Yves d'Udekem tỷ lệ BN bị thất bại Fontan sau 8,5 năm là $13,77 \%$ [2]. Để chẩn đoán thất bại Fontan không chỉ biểu hiện các triệu chứng do tổn thương tim mà còn có biểu hiện của các cơ quan khác. Ngày nay vẫn chưa có các tiêu chuẩn cụ thể để chẩn đoán thất bại Fontan song có thể dựa vào các tiêu chí sau: suy tim nặng (độ III, IV), hở van nhĩ thất vừa hoặc nặng có triệu chứng lâm sàng, tím nặng môi và đầu chi, tăng áp lực ĐMP, các triệu chứng của tăng áp lực tĩnh mạch cửa, xơ gan [26],[13]. Điều trị phụ thuộc vào nguyên nhân của thất bại có thể sử dụng thuốc (lợi tiểu, vận mạch, hạ áp lực ĐMP), sửa van hoặc thay van nhĩ thất, gỡ bỏ phẫu thuật Fontan (Taken-down Fontan), ghép tim [13].

\section{V.KẾT LUẬN:}

Kết quả trung hạn phẫu thuật Fontan với ống nối ngoài tim bằng mạch nhân tạo tốt, tỷ lệ biến chứng muộn thấp.

\section{TÀI LIỆU THAM KHẢO}

1. Kanakis, M. A., Petropoulos, A. C., and Mitropoulos, F. A. (2009), "Fontan operation", Hellenic J Cardiol. 50(2), pp. 133-41.

2. d'Udekem, Y., et al. (2007), "The Fontan procedure: contemporary techniques have improved long-term outcomes", Circulation. 116(11 Suppl), pp. I157-64.

3. Jonas, Richard A. (2004), "Comprehensive Surgical Management of Congenital Heart Disease Hachette UK Company,338 Euston Road, London". the fisrt. 
4. J. Stark, M.de Leval and VT Tsang (2006), " Surgery for Congenital Heart Defect," John Wiley \& Sons, London. third edition.

5. Ocello, S., Salviato, N., and Marcelletti, C. F. (2007), "Results of 100 consecutive extracardiac conduit Fontan operations", Pediatr Cardiol. 28(6), pp. 433-7.

6. Ganigara, M., et al. (2010), "Extracardiac Fontan operation after late bidirectional Glenn shunt", Asian Cardiovasc Thorac Ann. 18(3), pp. 253-9.

7. G.S. Haas, H. Hess (2000), "Extracardiac conduit Fontan procedure: early and intermediate results", European Journal of Cardio-thoracic Surgery. 17, pp. 648-654.

8. s, Pa n a g i o t i s G. Sf yri di (2010), "The Fontan Procedure in Greece: Early Surgical Results and Excellent Mid-Term Outcome", Hellenic J Cardiol. 51, pp. 323-329.

9. Chowdhury, U. K., et al. (2005), "Specific issues after extracardiac fontan operation: ventricular function, growth potential, arrhythmia, and thromboembolism", Ann Thorac Surg. 80(2), pp. 665-72.

10. Kim, S. J., et al. (2008), "Outcome of 200 patients after an extracardiac Fontan procedure", J Thorac Cardiovasc Surg. 136(1), pp. 108-16.

11. Adachi, I., et al. (2007), "Preoperative small pulmonary artery did not affect the midterm results of Fontan operation", Eur $J$ Cardiothorac Surg. 32(1), pp. 156-62.

12. Ovroutski, S., et al. (2003), "Early and medium-term results after modified Fontan operation in adults", Eur J Cardiothorac Surg. 23(3), pp. 311-6.
13. Deal, Barbara J (2012), "Management of the failing Fontan circulation", Heart. 98, pp. 1098-1104.

14. Marrone C, Galasso G, Piccolo R, de Leva F (2011), " Antiplatelet versus anticoagulation therapy after extracardiac conduit Fontan: a systematic review and meta-analysis", Pediatr Cardiol. 32, pp. 32 - 39.

15. Rosenthal DN, Friedman AH, Kleinman CS (1995), "Thromboembolic complications after Fontan operations", Circulation. 92(2), pp. 287-293.

16. Monagle P, Karl TR (2002), "Thromboembolic problems after the Fontan operation", Semin Thorac Cardiovasc Surg Pediatr Card Surg Annu. 5, pp. 36-47.

17. Rosenthal, D. N., et al. (1995), "Thromboembolic complications after Fontan operations", Circulation. 92(9 Suppl), pp. II287-93.

18. Shirai, L. K., et al. (1998), "Arrhythmias and thromboembolic complications after the extracardiac Fontan operation", J Thorac Cardiovasc Surg. 115(3), pp. 499-505.

19. Jacobs, M. L. and Pourmoghadam, K. K. (2007), "Thromboembolism and the role of anticoagulation in the Fontan patient", Pediatr Cardiol. 28(6), pp. 457-64.

20. Lee, J. R., et al. (2007), "Comparison of lateral tunnel and extracardiac conduit Fontan procedure", Interact Cardiovasc Thorac Surg. 6(3), pp. 328-30.

21. Azakie, A., et al. (2001), "Extracardiac conduit versus lateral tunnel cavopulmonary connections at a single institution: impact on outcomes", J Thorac Cardiovasc Surg. 
122(6), pp. 1219-28.

22. Mertens, L., et al. (1998), "Protein-losing enteropathy after the Fontan operation: an international multicenter study. PLE study group", J Thorac Cardiovasc Surg. 115(5), pp. 1063-73.

23. LSK KWOK, YF CHEUNG, TC YUNG,AKT CHAU,CSW CHIU (2002), "Protein-Losing Enteropathy after Fontan Procedure", HK J Paediatr. 7, pp. 85-91.

24. Veldtman, G. R. and Webb, G. D. (2014),
"Improved survival in Fontan-associated protein-losing enteropathy", $J$ Am Coll Cardiol. 64(1), pp. 63-5.

25. John, A. S., et al. (2014), "Clinical outcomes and improved survival in patients with protein-losing enteropathy after the Fontan operation", J Am Coll Cardiol. 64(1), pp. 54-62.

26. McRae, Marion E. (2013), "long-term Issues after the Fontan Procedure", AACN Advanced critical care. 24(3), pp. 264-282. 